\title{
Aeromagnetic constraints on the subsurface structure of the Unzen Graben, Kyushu, Japan
}

\author{
Ayako Okubo ${ }^{1}$, Tadashi Nakatsuka ${ }^{2}$, Yoshikazu Tanaka ${ }^{3}$, Tsuneomi Kagiyama ${ }^{3}$, and Mitsuru Utsugi ${ }^{3}$ \\ ${ }^{1}$ Disaster Prevention Research Institute, Kyoto University, Kyoto 611-0011, Japan \\ ${ }^{2}$ Geological Survey of Japan, AIST, 1-1-1 Higashi, Tsukuba 305-8567, Japan \\ ${ }^{3}$ Institute for Geothermal Sciences, Graduate School of Science, Kyoto University, Kumamoto 869-1404, Japan
}

(Received March 17, 2005; Revised August 16, 2005; Accepted August 16, 2005; Online published January 27, 2006)

\begin{abstract}
Aeromagnetic analyses have been conducted in and around the Unzen Volcano, Kyushu, Japan, in order to reveal the subsurface structure of the Unzen graben. First, we applied a magnetization intensity mapping method to analyze the aeromagnetic anomalies of the central part of the Shimabara peninsula. Magnetization highs and lows correspond to the Older Unzen $(0.15-0.5 \mathrm{Ma})$ and the Younger Unzen $(<0.15 \mathrm{Ma})$, respectively. However, the Mayu-Yama volcano is exceptionally high in the Younger Unzen. Moreover, it turns out that the Pre-Unzen ( $>0.5 \mathrm{Ma}$ ) or localized hydrothermally altered areas show magnetization lows. Next, magnetic models were constructed from aeromagnetic anomalies, drilling data and the result of magnetization intensity mapping. Finally, similar to the results of other geophysical data, it turns out that the Unzen graben has the features of a half-graben, with the northern fault (the Chijiwa fault) down in the western Unzen region and the southern fault (the Futsu and Fukae fault) down in the eastern Unzen region. Moreover, it clarified that the layers of low magnetization extend to the near-surface beneath Shimo-Dake, Kami-Dake, and the Unzen hot spring. These layers of low magnetization reflect the fractured or hydrothermally altered zones caused by the upflow of geothermal convection that exists in the central part in the graben.
\end{abstract}

Key words: Aeromagnetic analyses, the Unzen graben, and magnetic structure.

\section{Introduction}

The Unzen Volcano (Fig. 1) has been formed in the Unzen graben in a north-south extensional tectonic stress field (Tada, 1984). This volcano is cut by east-west trending normal faults, such as the Chijiwa, Kanahama, Futsu and Fukae faults, in the central Shimabara peninsula of Kyushu Island, Japan. The northern and southern boundaries of the graben are not clear because volcanic rocks have almost entirely filled the depression. Recently, the Unzen volcano began phreatic eruptions, in November 1990, and yielded frequent pyroclastic flows until 1995. Thereby, the eastern Unzen region was covered with pyroclastic flows (Hoshizumi, 1999).

Rock magnetization depends on the difference in the sedimentary rock or the volcanic rock, or the generation process of volcanic rock. Moreover, it changes through geothermal activity. Therefore, aeromagnetic analysis is a powerful tool for seeing the subsurface distribution of tectonic and geothermal structures. The analysis can tell us 'how the Unzen volcano and the Unzen graben was formed' or 'in what place the volcanic activity has been generated' by clarifying the magnetic structure of the volcanic edifice. Moreover, future change of the structure associated with volcanic activity can be studied with repeat aeromagnetic surveys. Among previous aeromagnetic surveys in this region, only Nakatsuka (1994) presented an outline structure

Copyright (c) The Society of Geomagnetism and Earth, Planetary and Space Sciences (SGEPSS); The Seismological Society of Japan; The Volcanological Society of Japan; The Geodetic Society of Japan; The Japanese Society for Planetary Sciences; TERRAPUB of the graben from the data analysis of a high-altitude aeromagnetic survey in 1991. The analysis demonstrated the tendency that the part of the surface covered with magnetization highs forms deep inside the graben. The problem of Nakatsuka (1994) is that uniform magnetization was assumed for the whole of the Unzen Volcano and that geological information or drilling data were not considered.

Recently, information on the subsurface geology and ages of Unzen volcanic rocks was acquired in more detail by the Unzen Scientific Drilling Project (USDP). Drilling data of USDP especially clarified the growth history and subsurface structure of the Unzen Volcano (Uto et al., 2002; Hoshizumi et al., 2002). Therefore, we performed a more detailed magnetic analysis that reflects this geological information and existing drilling data to reveal the detailed subsurface structure of the volcano and its surrounding areas.

In this paper, we aim to clarify the magnetic structure of the Unzen graben, which has developed in close relationship with the volcanic activity, and to discuss the tectonic and geothermal subsurface structure based on these results. First, we reanalyzed the aeromagnetic data of August, 1991 (Nakatsuka, 1994) in order to clarify the regional spatial distribution of the geology in the central part of the Shimabara peninsula. Then, we reveal 2.5-dimensional models for three-dimensional interpretation and discuss these results based on the other geophysical and drilling data accumulated so far. 


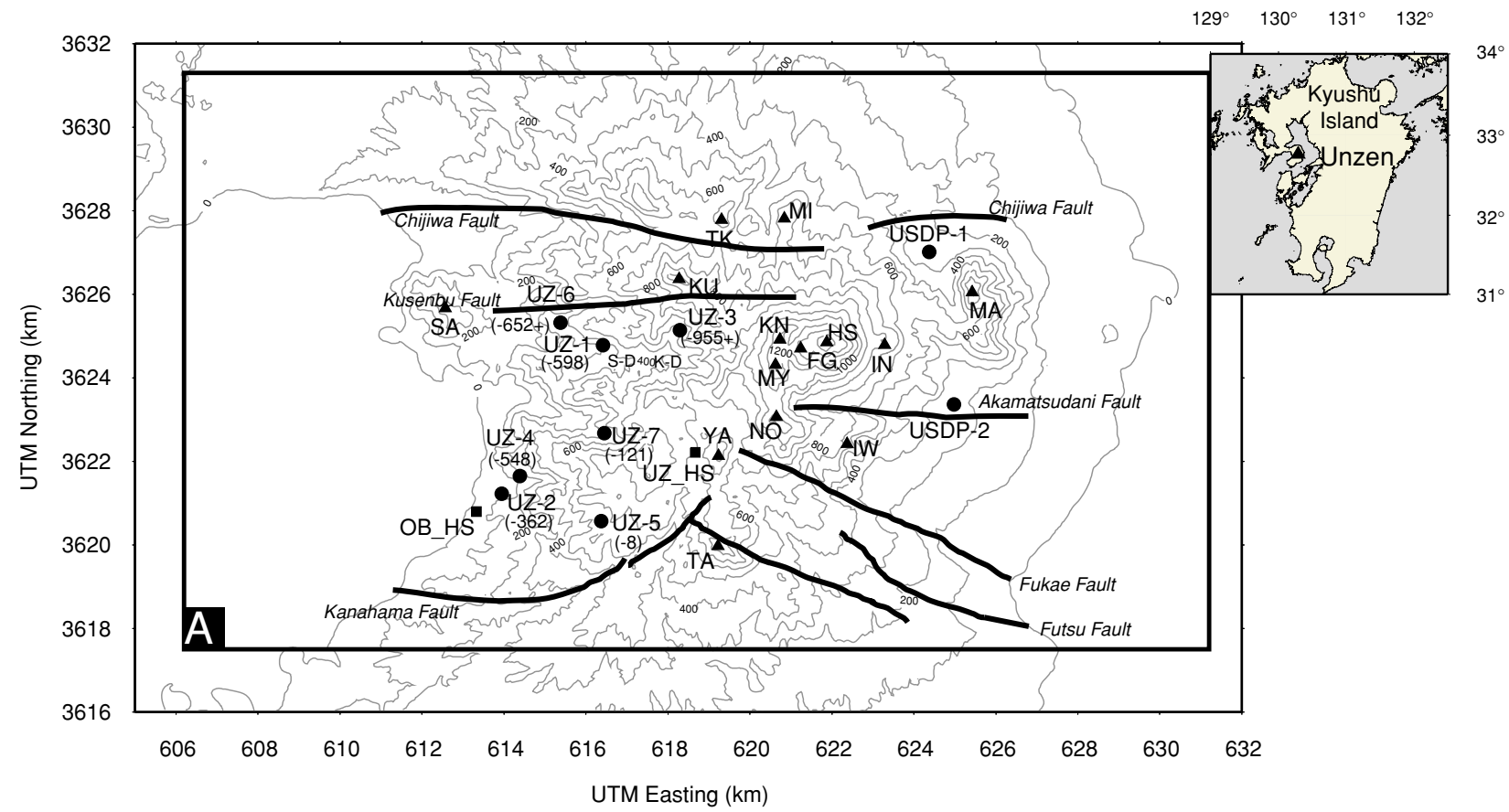

Fig. 1. Topographic map of the central Shimabara Peninsula. Contour interval is $100 \mathrm{~m}$. Box A shows the aeromagnetic data area used in this study. Solid circles of UZ-1 to 7, and USDP-1 and 2 show the locations of drilling sites and numerals show the altitude (above sealevel) of the top surface of the basement rocks of the Unzen volcano. Thick lines indicate normal faults after Hoshizumi et al. (2002). MA=Mayu-Yama; IN=Inao-Yama; IW=Iwatoko-Yama; FG=Fugendake; HS=Heisei-Shinzan; MI=Maidake; TK=Torikabuto-Yama; $\mathrm{KN}=$ Kunimidake; $\mathrm{KU}=$ Kusenbudake; $\mathrm{MY}=$ Myokendake; $\mathrm{NO}=$ Nodake; YA=Yadake; TA=Takaiwa-Yama; $\mathrm{SA}=\mathrm{Saruba-Yama}$ S-D=Shimo-Dake; $\mathrm{K}-\mathrm{D}=$ Kami-Dake; UZ-HS=Unzen hot spring; OB-HS=Obama hot spring.

\section{Geologic Framework}

The geology in the Unzen graben can be summarized, after Hoshizumi et al. (1999) and Hoshizumi et al. (2002), as follows. During the past 500,000 years, the Unzen Volcano has erupted lavas and pyroclastics of andesite and dacite composition in association with the development of volcano-tectonic graben. The Unzen Volcano can be divided into the Older Unzen (150-500 ka) and the Younger Unzen $(0-150 \mathrm{ka})$ volcanoes. The Younger Unzen volcano consists of the No-Dake, Myoken-Dake, Fugen-Dake, and Mayu-Yama volcanoes, in order of oldest to youngest (Fig. 1). As high ridges west of these volcanic edifices have acted as a topographic barrier, no volcanic products younger than $180 \mathrm{ka}$ have reached the western half of the Unzen Volcano. The Older Unzen volcano is exposed mainly in the western part of the Unzen volcano and underlies the Younger Unzen volcano in the eastern part. In addition, the Older Unzen volcano is characterized mainly by effusions of thick lava flows, while the Younger Unzen by the formation of lava domes and their collapsed pyroclastic deposits. The Pre-Unzen ( $>500 \mathrm{ka}$ ) volcanics reach to near the surface on the south of Kanahama fault (see Fig. 2). The drill holes UZ-1 to 6 showed the altitude (above sealevel) of the top surface of basement rocks of Unzen volcano (see Fig. 1). Recently, in the Unzen Scientific Drilling Project (USDP), two drillings USDP-1 and 2 penetrated the Unzen volcanic products and reached the Pre-Unzen pyroxene andesite of $500 \mathrm{ka}$ at depths of 680 and $1180 \mathrm{~m}$, respectively.

Inoue and Takemura (2002) inferred the outline of the subsurface structure around the Unzen volcano by twodimensional gravity data analysis with constraints of ge- ological data obtained from these drillings. Their result shows that the depth to the basement inside the graben is greater on the south side in the eastern Unzen, while the depth is greater on the north side in the western Unzen. The geological cross-section based on two sets of drilling data, USDP-1 and 2, also indicates that the depth is greater on the south side in the eastern foot of the Unzen volcano.

In geothermal areas, hydrothermal alteration typically destroys the magnetic signature of volcanic rocks either by completely removing the iron or by converting magnetite to hematite, which has a very low magnetic susceptibility (Finn and Morgan, 2002). The drilling data (UZ-1 to 6) of NEDO (1988) showed that the geothermal signs suggesting geothermal convection systems are distributed in the 'Unzen hot spring', 'Obama hot spring', and 'Shimo-Dake or Kami-Dake' inside the Unzen graben of the western Unzen region. In addition, hydrothermally altered material was found in those areas, and it was especially more remarkable around the Unzen hot spring, Kami-Dake and Shimo-Dake. An area of positive SP anomaly (NEDO, 1984; Hashimoto and Joint Research Group of Universities for Unzen Volcano, 1995a) is located around the Unzen hot spring, and expands in an east-west direction almost in parallel and about $1 \mathrm{~km}$ south of the Kusenbu fault. In the eastern part of the Unzen Volcano is the Shimabara hot spring which lies to the east of Mayu-Yama.

The magnetization derived from the magnetic survey is equivalent to the sum of the natural remanent magnetization (NRM) and induced magnetization. Here the total magnetization primarily reflects the variations in NRM intensity, because the NRM intensity in volcanic rock is gener- 


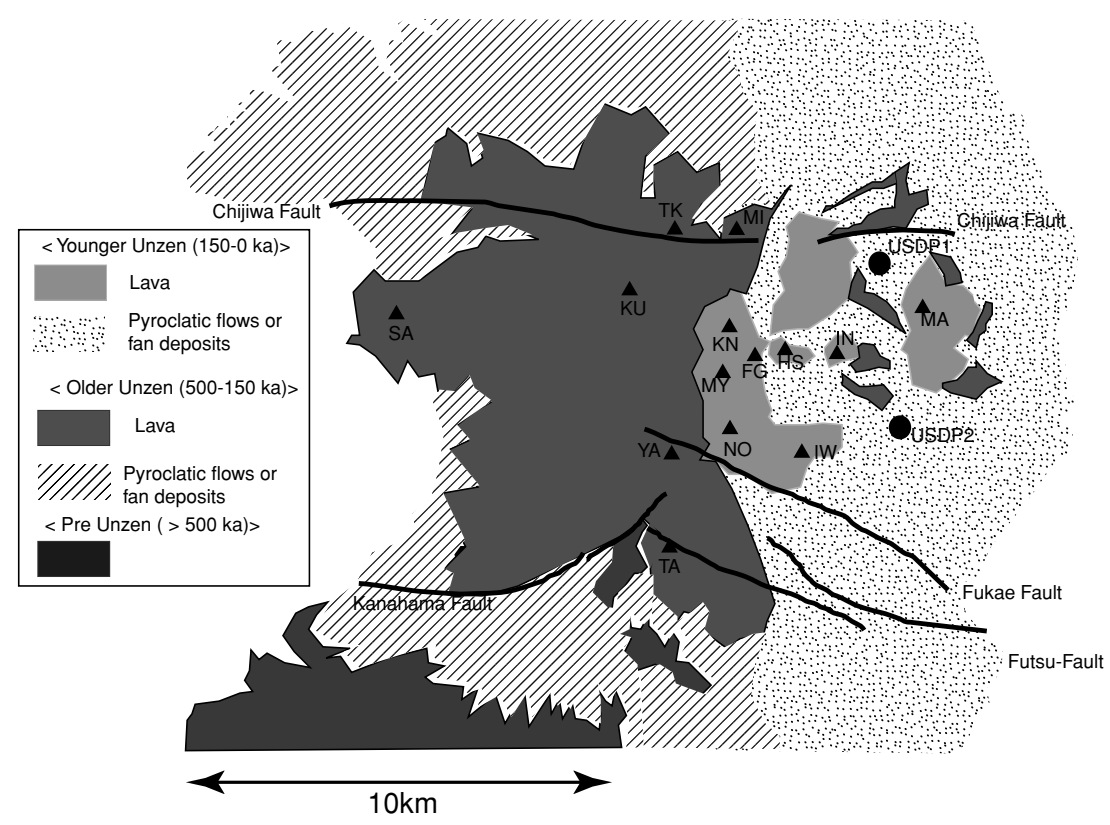

Fig. 2. Simplified geological map of the central Shimabara Peninsula, after Hoshizumi et al. (2002).

ally higher than induced magnetization. In a paleomagnetic study, Tanaka et al. (2004) measured NRM intensities of many specimens from the Unzen Volcano, and found that the NRM intensities of the Pre-Unzen are also smaller by one order of magnitude than the Younger or Older Unzens.

\section{Aeromagnetic Data}

Concerning the Unzen Volcano, among several data sources of aeromagnetic surveys conducted at different times with varying survey specifications (NEDO, 1988; Nakatsuka, 1994; Mogi et al., 1995; Okubo et al., 2005), the following data set is useful to discuss the tectonic and geothermal subsurface structure of the Unzen graben.

An aeromagnetic survey covering the central part of the Shimabara peninsula was carried out in August, 1991, after the commencement of a recent eruption (Nakatsuka, 1994). Although it was before the formation of the Heisei Dome, the data from this survey is still useful, because we don't discuss the Heisei Dome in this report. A total of 26 traverse lines in the E-W direction and five tie lines in the N-S direction were recorded at an altitude of $7500 \mathrm{ft}(2300 \mathrm{~m})$ above sealevel. Average line spacing of the traverse lines is about $500 \mathrm{~m}$, uncovering above the summit lava dome. Nakatsuka (1994) did the data reduction and the analysis as follows: (1) The data were corrected for the diurnal variations of the magnetic field, (2) values of the International Geomagnetic Reference Field (IGRF 1990) were removed from the data, (3) the average terrain magnetization was estimated as $2.9 \mathrm{~A} / \mathrm{m}$ from the statistical analysis, and (4) the terraincorrected anomaly was derived as a result of subtracting the effect of the uniform magnetization of the terrain. This terrain-corrected anomaly is shown in Fig. 3. Nakatsuka (1994) presented a three-dimensional rough model of the graben from the analysis of the terrain-corrected anomaly. However, further analysis including geological data was not carried out.

Therefore, in order to discuss the tectonic and geother- mal subsurface structure in the Unzen graben in more details, we have re-analyzed the same data. New magnetic modeling was performed based on the results of magnetization intensity mapping in combination with drilling data of UZ-1 to 6 and USDP-1 and 2.

\section{Magnetization Intensity Mapping}

The methods of magnetization intensity mapping were applied to the data after removing the effect of the topographic relief of the uniformly magnetized terrain, and the model of the distribution of magnetization intensities was derived by inverse analysis. There are a lot of examples leading to an effective analytical result (e.g. Okuma et al., 1994; Nakatsuka, 1995; Okuma, 1998; Okubo et al., 2005).

Therefore, in order to obtain information on the regional subsurface structures such as lavas, pyroclastic flows, and fractured or hydrothermally altered areas, we also applied a magnetization intensity mapping on the assumption that the magnetic anomalies are caused by the terrain magnetized in the same direction as the Earth's magnetic field (a reasonable assumption given the young $(<0.3 \mathrm{Ma})$ age of the Unzen) and the magnetization intensity varies only laterally. We will now describe this method.

First, we considered the magnetic anomalies caused by an assembly of prismatic bodies forming the volcanic terrain (Fig. 4). The total anomaly $g_{i}$ for all prismatic bodies can be written as

$$
g_{i}=\sum_{j=1}^{m} w_{i j} \cdot J_{j} \quad(i=1,2, \ldots, n) .
$$

Here, $w_{i j}$ is the geometrical factor of the $j$ th source prism for the $i$ th observation point (Bhattacharyya, 1964) and $J_{j}$ indicates magnetization of the $j$ th prism. $n$ and $m$ denote the number of observation points and the number of source prisms, respectively.

If we have the observation $f_{i}(i=1,2, \ldots, n)$ of the 


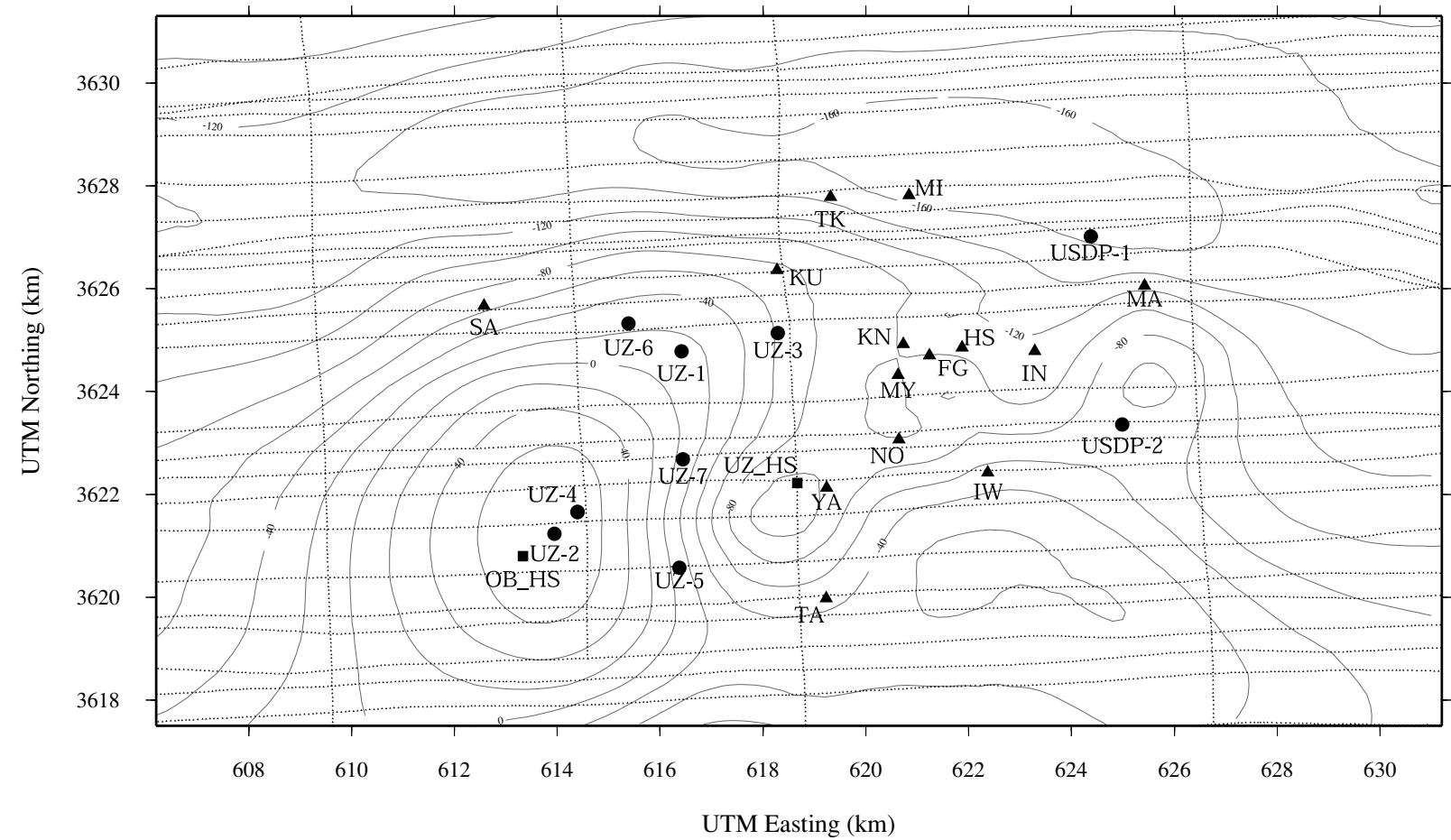

Fig. 3. Terrain-corrected magnetic anomalies at a flying altitude of $2300 \mathrm{~m}$ above sealevel for box A shown in Fig. 1, from the aeromagnetic survey of 1991 (Nakatsuka, 1994). Contour interval is $20 \mathrm{nT}$. Dotted lines indicate track-line paths.

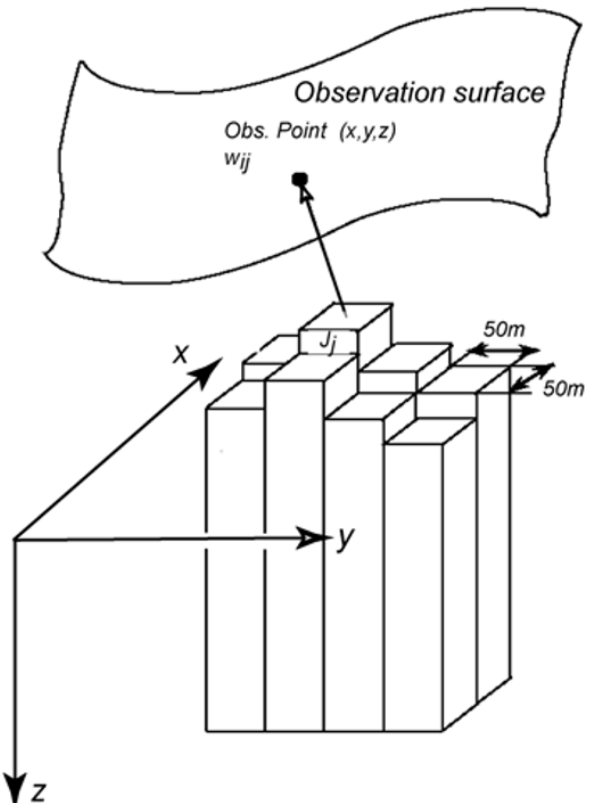

Fig. 4. Schematic configuration of the terrain model used for the magnetization intensity mapping. $J_{j}$ : Magnetization of the $j$ th a source prism, $w_{i j}$ : the geometric contribution factor of the $j$ th source prism against the magnetic anomaly at the $i$ th observation point $(x, y, z)$.

magnetic anomaly, the magnetization intensity distribution $J_{j}(j=1,2, \ldots, m)$ can be solved from $n$ simultaneous linear equations

$$
\sum_{j=1}^{m} w_{i j} \cdot J_{j}=f_{i} \quad(i=1,2, \ldots, n) .
$$

In this study, as we deal with the case of $m<n$, Equa- tion (2) has no exact solution and usually a least-squares method is used to estimate $J_{j}(j=1,2, \ldots, m)$. Here we employed the conjugate gradient (CG) method (Nakatsuka, 1995; Okuma, 1998) instead directly of solving Equation (2). The CG method also gives a least-squares solution.

We applied this method to the anomalies of Fig. 3 employing the following configuration of assumed prismatic bodies:

1) We divided the terrain into a mesh of $300 \mathrm{~m}$ squares, and the vertical extent from the surface to $2 \mathrm{~km}$ below sealevel was considered. The top face undulation represented by $50 \mathrm{~m}$-grid topography was taken into account.

2) The prismatic bodies are arranged to cover an area 1.5 $\mathrm{km}$ beyond the survey area in order to avoid edge effects.

\subsection{Results}

As the data analyzed are those after terrain correction, the analysis gives magnetization differences from the average magetization adopted for the terrain correction. Bellow we describe the values of magnetization after adding this average of $2.9 \mathrm{~A} / \mathrm{m}$. This procedure is equivalent to analyzing the observed magnetic anomaly (before terrain correction) with the starting model of uniformly magnetized terrain of $2.9 \mathrm{~A} / \mathrm{m}$. Characteristics of the obtained regional magnetization intensity distribution in the central part of the Shimabara peninsula (Fig. 5) are summarized as follows.

For the western Unzen region, generally, magnetization highs (about $4.5 \mathrm{~A} / \mathrm{m}$ ) predominate on the Older Unzen volcano, for example, around Saruba-Yama. However, magnetization lows (about $1.0 \mathrm{~A} / \mathrm{m}$ ) occur around the Unzen hot spring, and extend in an east-west direction on the south side of the Kusenbu fault. These areas correspond to the hydrothermal altered areas, causing a large loss of magnetic minerals in the volcanic rocks. 


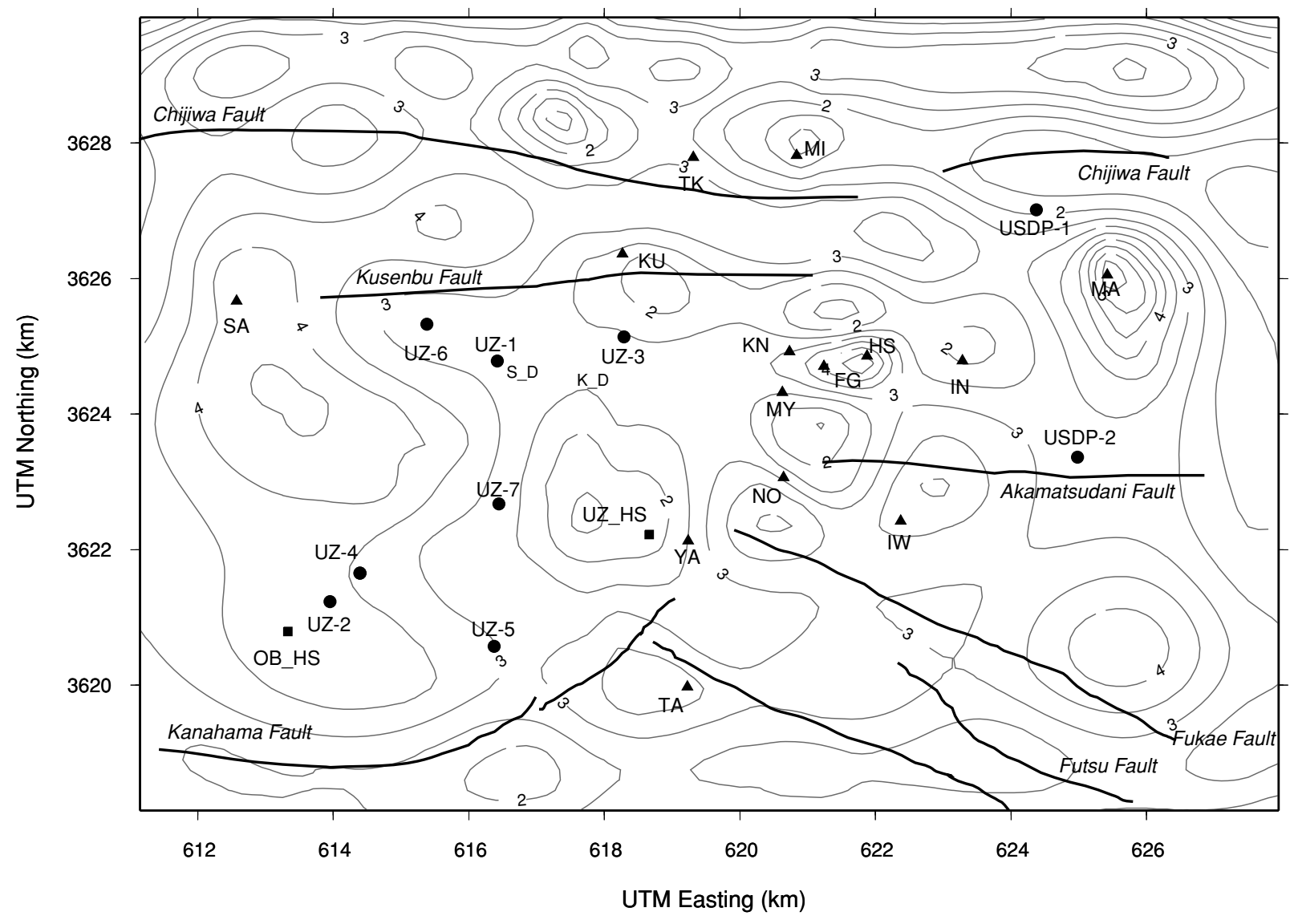

Fig. 5. Result of magnetization intensity mapping for box A. The terrain-corrected anomalies of Fig. 3 were the input data for the inversion process.

On the other hand, for the eastern Unzen region, magnetization highs (about $6 \mathrm{~A} / \mathrm{m}$ ) predominate at the MayuYama volcano, while magnetization lows (about $1.0 \mathrm{~A} / \mathrm{m}$ ) predominate on the circumference of Mayu-Yama. We conclude that the Mayu-Yama lava has the highest magnetization on the Unzen Volcano. The fan deposit located between the Mayu-Yama volcano and the Fukae fault shows magnetization highs, and there is a clear magnetization intensity associated with the Fukae fault. This suggests that magnetic fan deposits have thickly accumulated inside the graben.

Magnetization lows predominate outside the main faults forming the Unzen graben (i.e., to the north of the Chijiwa fault, and to the south of the Kanahama, Fukae, and Futsu faults). However, magnetization highs are distributed with an east-west trend north of the Chijiwa fault. It is considered to be the effect of lavas on the Older Unzen volcano, which extend beyond the graben (see Fig. 2), because the eruption rate was greater than the subsidence. Moreover, it is suggested that the magnetization of the Pre-Unzen must be weak (about $1.0 \mathrm{~A} / \mathrm{m}$ ) because the Pre-Unzen volcanics occur near the surface south of the Kanahama fault (see Fig. 2).

Generally, the above results have a good correlation with the surficial measurements of NRM intensity (Tanaka, personal communication; Tanaka et al., 2004).

\section{Forward Modeling for Magnetic Structure}

From the results of the magnetization intensity mapping, we were able to guess that the magnetization intensity of the Older Unzen is strong, and the Pre-Unzen, the Younger Unzen, and the hydrothermal altered area are weak. Although the magnetization intensity mapping mainly reflects the general distribution of magnetization near the surface, it does not give information on the depth. Actually, magnetic anomalies also reflect the thickness of the magnetic layer. The lack of a unique solution is inherent in potential field data, and it is difficult to decide both "the thickness change of magnetic layer" and "the lateral variation of magnetization" from magnetic anomalies. Therefore, we thought, judging from the geological condition, that it was suitable to consider the thickness change of the uniformly magnetized layer, in order to clarify the subsurface structure of the Unzen graben and the volcanic activity based on it.

In order to simplify the modeling process, terrain reduced-to-pole aeromagnetic anomalies were derived from the terrain-corrected anomalies in Fig. 3 using the method of Baranov and Naudy (1964) (see Fig. 6). Then, we used a 2.5-dimensional, foward-and-inverse magnetic profile modeling program (Webring, 1985) along the profiles crossing the main anomalies shown in Fig. 6. The total magnetization used in this forward calculation is a vector sum of the induced and remanent magnetization. All the selected profiles, produced by slicing this terrain reduced-to-pole magnetic anomaly grid assume that both the magnetic field and the magnetization vector are vertical. The magnetization values discussed below are those after adding average terrain magnetization of $2.9 \mathrm{~A} / \mathrm{m}$.

The two-layer models along profiles 1 to 6 were con- 


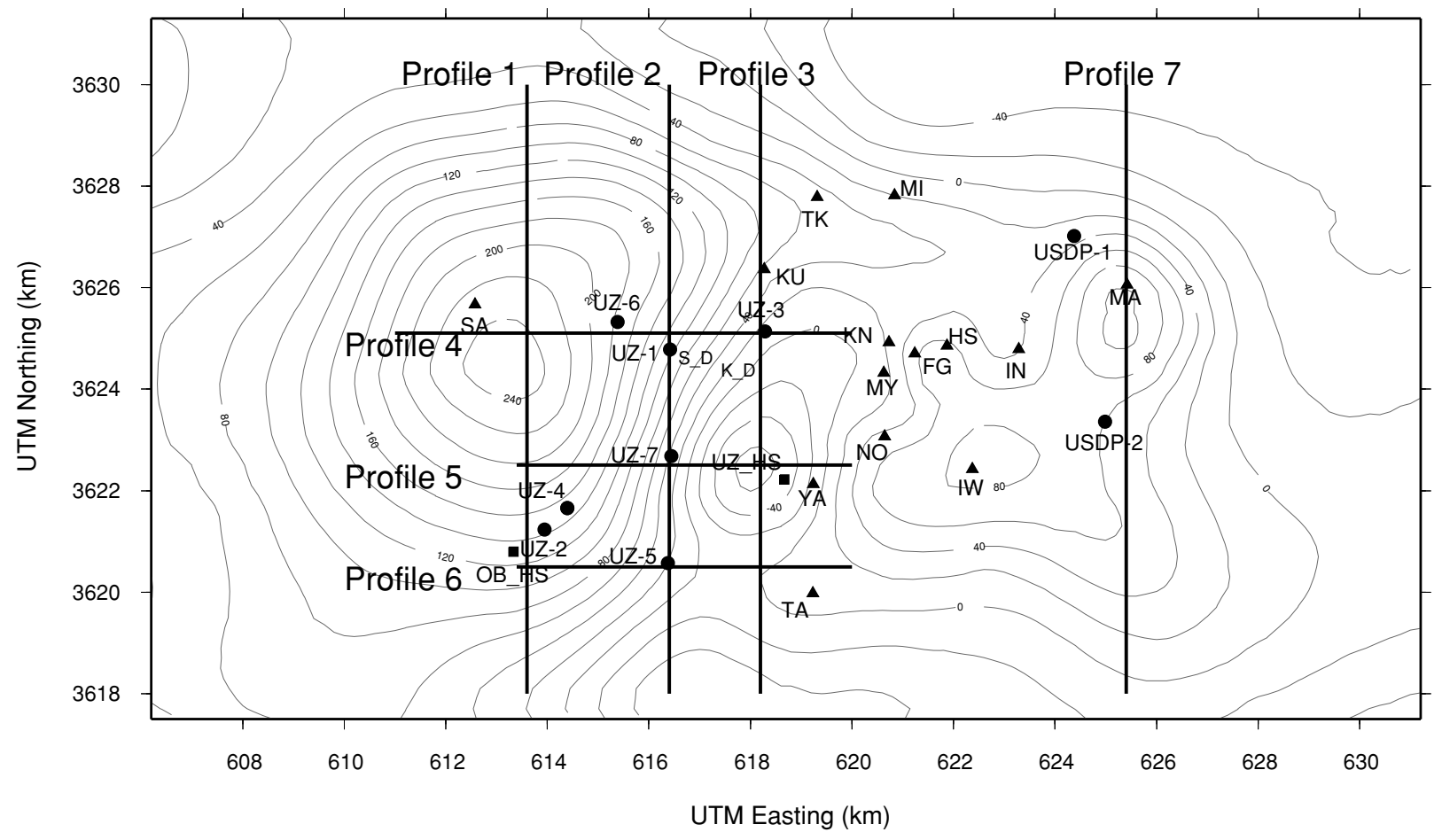

Fig. 6. Terrain-corrected reduced-to-pole magnetic anomaly map of box A, and the locations of profiles of forward modeling. Contour interval is $20 \mathrm{nT}$.

Table 1. Values of magnetization intensity used for forward calculations based on Fig. 5.

\begin{tabular}{lc}
\hline Geological feature & Magnetization $(\mathbf{A} / \mathbf{m})$ \\
\hline the Pre Unzen volcanics & 1.0 \\
the Older Unzen volcanics & 4.5 \\
the Younger Unzen volcanics & 1.0 \\
Mayu-Yama volcanics & $4.5-6.0$ \\
Hydrothermally altered or fractured area & 1.0 \\
\hline
\end{tabular}

structed as shown in Fig. 7, so as to match the magnetic anomalies and drilling data. We adopted the average magnetization intensities of $4.5 \mathrm{~A} / \mathrm{m}$ for the Older Unzen volcano lava, and $1 \mathrm{~A} / \mathrm{m}$ for the layers of the Pre-Unzen volcanics and the hydrothermally altered area, based on the result of the magnetization intensity mapping (Fig. 5). For profile 7 (Fig. 6) in the eastern Unzen region, modeling was performed considering the Younger Unzen and the MayuYama lava, in addition to the above. From the result of magnetization intensity mapping (Fig. 5), the magnetization intensity of the Mayu-Yama lava was assumed to be 4.5-6 A/m, while the Younger Unzen, consisting mainly of collapsed or lahar products of No-Dake, Myoken-Dake and Fugen-Dake, was assumed to be $1 \mathrm{~A} / \mathrm{m}$. The values of magnetization intensity used for forward calculations are shown in Table 1. For the drilling sites along profiles 1 to 7 , the boundary depths between the Older Unzen and the Pre-Unzen (after Hoshizumi et al., 2002) were adopted as the control points (see Fig. 1). However, as drill holes UZ3 and UZ-6 did not reach the Pre-Unzen, they contributed only towards restricting the Older Unzen thickness. The constructed models are illustrated in Figs. 7 and 8 in the form of cross-sections.

\subsection{Results}

The north-south sections along profiles $1-3$ in the western Unzen region are shown in Fig. 7(a)-(c). In profile 1, a layer of $4.5 \mathrm{~A} / \mathrm{m}$ is thickly deposited inside the graben bordered at the Chijiwa and the Kanahama faults. However, in profile 2, the layer of $4.5 \mathrm{~A} / \mathrm{m}$ is thinner around the Kanahama fault while it is thicker around the Chijiwa fault. In profile 3 , there is the same tendency as profile 2 , although the layer of $1.0 \mathrm{~A} / \mathrm{m}$ reaches the surface around Unzen hot spring.

The east-west sections along profiles $4-6$ in the western Unzen region are shown in Fig. 7(d)-(f). In Profile 4, the layer of $4.5 \mathrm{~A} / \mathrm{m}$ becomes thinner to the east, from UZ-1 to Kami-Dake, and further east from Shimo-Dake. In profile 5 , although the layer of $4.5 \mathrm{~A} / \mathrm{m}$ is thick in the western part, the layer of $1.0 \mathrm{~A} / \mathrm{m}$ reaches the surface around the Unzen hot spring, as in profile 3 . In profile 6 , the thickness variation of the layer of $4.5 \mathrm{~A} / \mathrm{m}$ becomes a little calmer, still having the same tendency in profile 5 .

In the north-south section along profile 7 in the eastern Unzen region (Fig. 8), forward modeling was performed dividing the magnetization intensity of the Mayu-Yama lava in the case of $4.5 \mathrm{~A} / \mathrm{m}$ (Case 1; Fig. 8(a)) and $6 \mathrm{~A} / \mathrm{m}$ (Case 2; Fig. 8(b)). In Case 1, the residual of the calculation value 

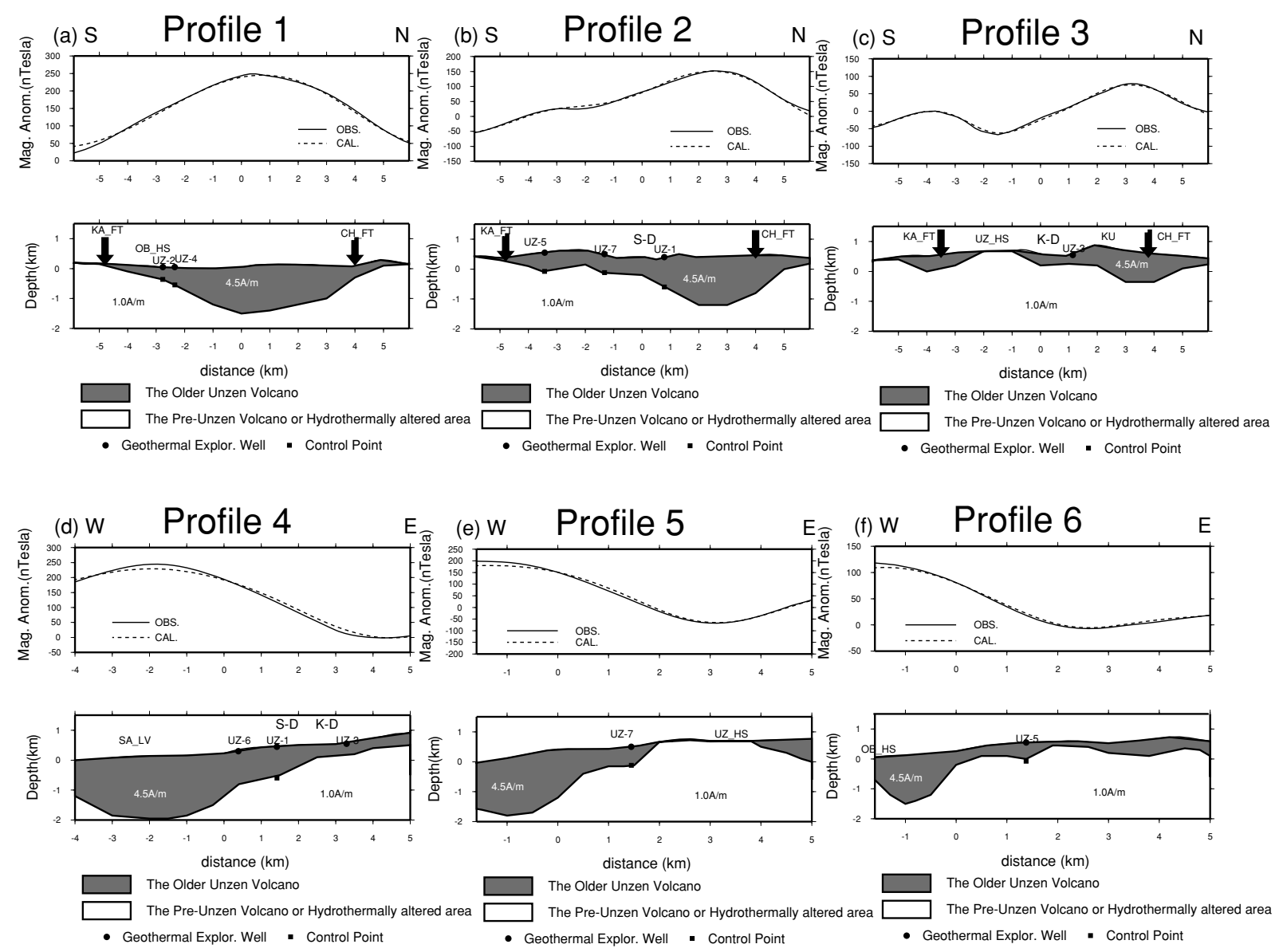

Fig. 7. Results of the magnetic modeling along the N-S profiles [(a) profile 1, (b) profile 2 and (c) profile 3] and the E-W profiles [(d) profile 4, (e) profile 5 and (f) profile 6] shown in Fig. 6. Squares indicate the control points used for modeling after NEDO (1988).

and the observation value becomes large around the control point of USDP-2. On the other hand, as for the difference between the calculated and observed values of Case 2, about 6.0 nT is smaller than Case 1 around USDP-2, as shown in Fig. 8. Therefore, we decided to make Case 2 the final model. It was shown that the magnetization low is deep in the area placed between the Chijiwa fault and Futsu and Fukae fault, magnetization high occupies the inside, and the south is deeper. In addition, magnetization high area exists in Mayu-Yama.

\section{Discussion}

It is pointed out from analysis of the geology (Hoshizumi et al., 2002) and gravity (Inoue and Takemura, 2002), that there are different features of the geologic structure between west and east of the Unzen region. Here, we discuss the subsurface structure of the Unzen graben in each region.

\subsection{Western Unzen region}

The Chijiwa and Kanahama faults are known to be the basic frame for the graben in the western Unzen region. From our result of Fig. 7, it is suggested that the lava and pyroclastic flow deposits of the Older Unzen are associated with the subsidence of the basement near the Chijiwa fault, while the subsidence of the basement is not clear at the Kanahama fault. This result indicates that the northern and southern faults forming the Unzen graben, have different characters, and our result suggests that the subsurface structure in the western Unzen region is a half-graben which has fallen at the northern fault. Also from the results of a MT survey by Utada et al. (1994) and Kagiyama et al. (1992), it is known that a thick layer of high resistivity exists near the Chijiwa fault, while a layer of low resistivity exists under the surface near the Kanahama fault. In other words, they showed that the fault on the north side (the Chijiwa fault) and one on the south side (the Kanahama fault) were asymmetric structures like this. Therefore, the half-graben model is also consistent with the results of the MT survey.

On the other hand, magnetization lows (about $1 \mathrm{~A} / \mathrm{m}$ ) predominate around the Unzen hot spring, Shimo-Dake and Kami-Dake. It is difficult to distinguish whether they are caused by the Older Unzen or the Pre Unzen (basement) from aeromagnetic data only. In particular, our magnetic model demonstrated that the layer of low magnetization (1 $\mathrm{A} / \mathrm{m}$ ) extends near the surface beneath Kami-Dake, ShimoDake and the Unzen hot spring (Fig. 7). According to drilling data (NEDO, 1988) at UZ-3 and other sites, the layer generally corresponds to the hydrothermal alteration of fractured rocks. Kagiyama et al. (1992) also showed that the layer of low resistivity becomes extremely shallow around the Unzen hot spring to reach the surface at that spring. Therefore, it is thought that the rises of the low magnetization layer correspond to the fractured or hydrothermally altered zones caused by the upflow of geothermal convection. Thus, the layer of low magnetization dominates 

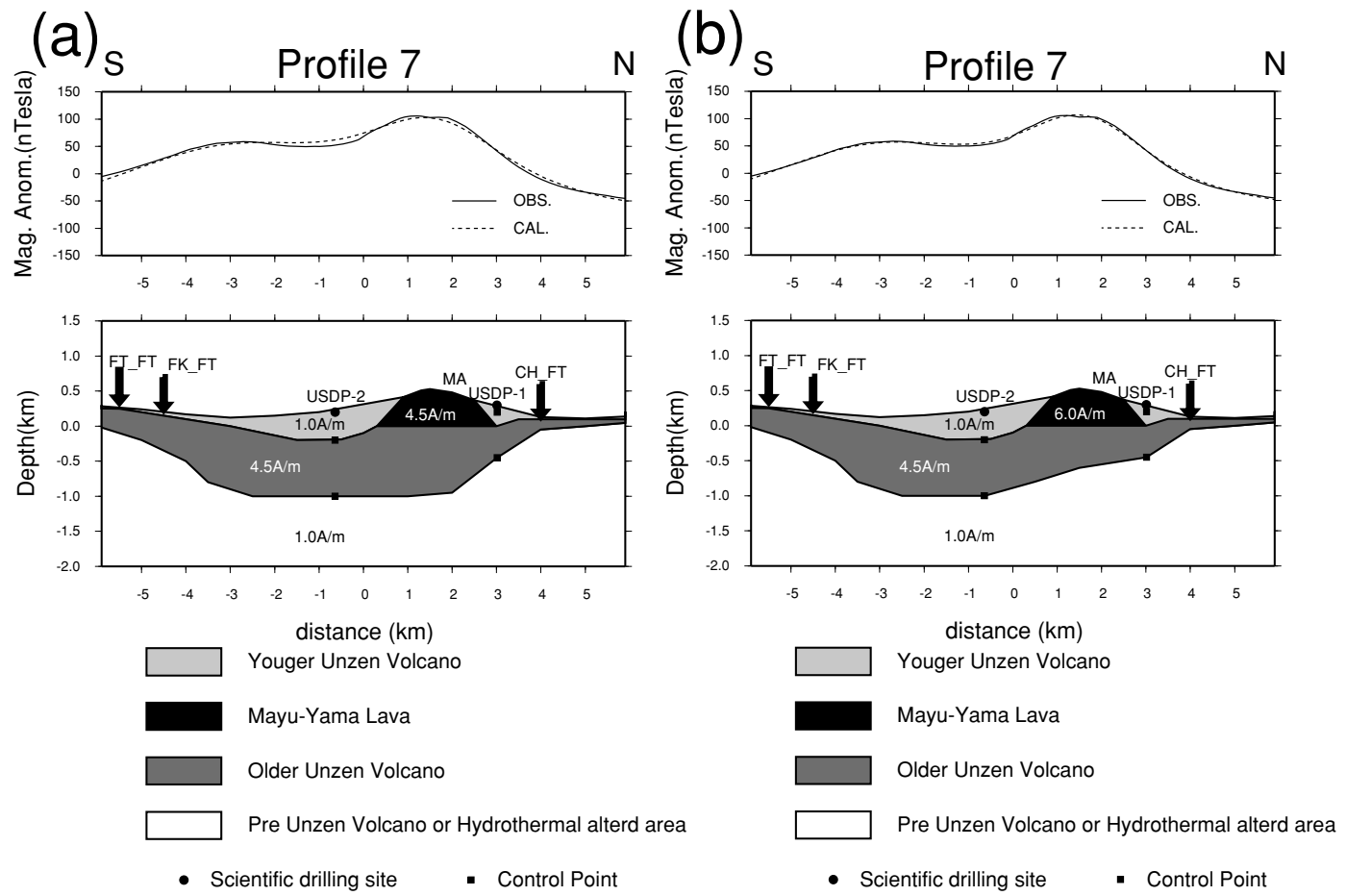

Fig. 8. Results of the magnetic modeling along profile 7 shown in Fig. 6. Squares indicate the control points used for modeling, after Hoshizumi et al. (2002). (a) Case 1: Mayu-Yama lava $=4.5 \mathrm{~A} / \mathrm{m}$; (b) Case 2: Mayu-Yama lava $=6.0 \mathrm{~A} / \mathrm{m}$.

at the Unzen hot spring and at the area from Shimo-Dake to Kami-Dake, reflecting hydrothermal alteration (Figs. 5, 7(c) and (e)). However, no magnetization lows are found at the Obama hot spring (Figs. 5, 7(a) and (f)). It is therefore expected that the scale of the geothermal convection system at the Obama hot spring is much smaller than that for the Unzen hot spring.

\subsection{Eastern Unzen region}

In the volcanic fans extending southwards, we conclude that the basement was much depressed at the stage of the Older Unzen and a thick distribution of the Older Unzen products inside the graben (Fig. 8) exists beneath the younger deposits. In particular, it is shown in our magnetic analysis that the geological boundary is plainly seen along the Fukae fault (see Fig. 5). Moreover, it seems that the axis of the Unzen graben shifts to the south as one moves east in the Shimabara peninsula (Figs. 7 and 8). Thus, the magnetic structure in the western Unzen region is characterized by a half-graben down at the southern fault. The same tendency has also been shown in the geologic cross-section by Hoshizumi et al. (2003) and in the two-dimensional analysis of the gravity basement structure (Inoue and Takemura, 2002). The magnetization intensity of the Mayu-Yama lava give values much higher than other lavas in the Unzen Volcano, which is consistent with the results of the analysis from aeromagnetic data by Mogi et al. (1995). From the paleomagnetic study of Unzen, Tanaka (personal communication) measured the magnetic susceptibility based on the sample data in Fugen-Dake and Mayu-Yama, respectively, and it turns out that the value of Mayu-Yama (2006$\left.2135 \times 10^{-5} \mathrm{emu}\right)$ shows the result to be about two times higher than the value of Fugen-Dake $\left(1126-1349 \times 10^{-5}\right.$ emu). In addition, Miki, Kyoto Univ. (personal communi- cation) also measured the strength of the NRM intensity of Mayu-Yama, and gave a value of about $4.8 \mathrm{~A} / \mathrm{m}$.

\section{Concluding Remarks}

We conducted (1) a magnetization intensity mapping and (2) forward modeling of the subsurface structure, in order to better understand the magnetic subsurface structure of the Unzen graben.

The magnetization intensity map gives magnetization properties of volcanic rocks that relate to geological epoch, hydrothermal alteration, and the subsurface structure in the central Shimabara Peninsula. Magnetization highs of 4.5 $\mathrm{A} / \mathrm{m}$ predominate on the Older Unzen volcano exposed in the western Unzen region. For the eastern Unzen region, magnetization highs of $>6 \mathrm{~A} / \mathrm{m}$ on the Mayu-Yama volcano exceed the magnetization intensity of other lavas, reflecting the strength of NRM intensity.

The magnetic models based on drilling data and geological information have demonstrated that the Unzen graben is best characterized as a half-graben (Fig. 9(a)). That is, the Chijiwa fault in the north has thick sediment in the western Unzen region (Fig. 9(b)), and the Fukae fault in the south has thick sediment in the eastern Unzen region (Fig. 9(c)). Moreover, it shows that magnetization lows extend to near the surface beneath Kami-Dake, Shimo-Dake and the Unzen hot spring (Fig. 9(b)). The extent of these lows constrain the locations of modern and past hydrothermal activity in individual areas.

Acknowledgments. We are grateful to N. Oshiman, Kyoto Univ., H. Hoshizumi, GSJ., K. Takemura, Kyoto Univ., N. Kitada, Kyoto Univ., H. Shimizu, Kyushu Univ., and T. Matsushima, Kyushu Univ., for useful discussions and helpful criticism. We also thank 


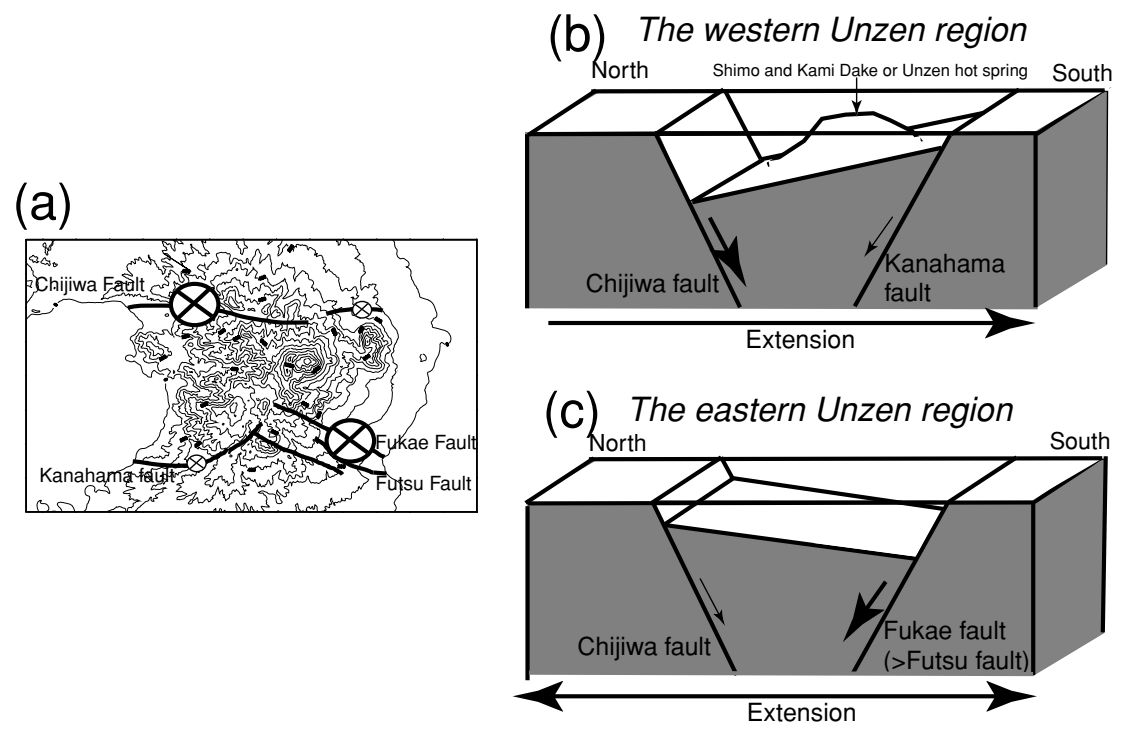

Fig. 9. (a) The model for subsidence of main faults forming the Unzen graben. The size of circle symbols and thickness of downward arrows indicates the relative amounts of subsidence. (b) Schematic picture of magnetic model of subsurface structure for the western region of Unzen, and (c) for the eastern region of Unzen.

N. Kitada, H. Shimizu and T. Matsushima for their help in the aeromagnetic survey on September 18, 2002. We would like to thank H. Tanaka, Kochi Univ., H. Shibuya, Kumamoto Univ., and D. Miki, Kyoto Univ., for providing us with the NRM intensity data of the Unzen paleomagnetism sample. We express our appreciation to James Mori, Kyoto Univ., for his help in improving the quality of the manuscript. We are also thankful to R. W. Saltus, USGS., and the anonymous reviewer for reviewing our paper and giving us valuable comments.

\section{References}

Baranov, V. and H. Naudy, Numerical calculation of the formula of reduction to the magnetic pole, Geophysics, 29, 67-79, 1964.

Bhattacharyya, B. K., Magnetic anomalies due to prism-shaped bodies with arbitrary polarization, Geophysics, 29, 517-531, 1964.

Finn, A. C. and L. A. Morgan., High-Resolution aeromagnetic mapping of volcanic terrain, Yellowstone National Park, J. Volcanol. Geotherm. Res., 115, 207-231, 2002.

Hashimoto, T. and Joint Research Group of Universities for Unzen Volcano, Searching the conduit of Unzen Volcano using selfpotential anomalies, Report of Grant-in-Aid for Scientific Research (No. 06306011; Ohta, K.), 80-86, 1995a (in Japanese).

Hoshizumi, H., K. Uto, and K. Watanabe, Geology and eruptive history of Unzen volcano, Shimabara Peninsula, Kyushu, SW Japan, J. Volcanol. Geotherm. Res., 89, 81-94, 1999.

Hoshizumi, H., K. Uto, A. Matsumoto, S. Shu, A. Kurihara, and T. Sumii, History of formation of Unzen volcano, Chikyu Monthly, 24(12), 828834, 2002 (in Japanese).

Hoshizumi, H., K. Uto, and A. Matsumoto, Geology and petrology of Unzen volcano. Field Guidebook, A3: Unzen and Aso Volcanoes, XXIII General Assembly of the International Union of Geodesy and Geophysics, p. 11-19, 2003.6.

Inoue, N. and K. Takemura, Subsurface structure around Unzen volcano based on gravity and geological data, Institute for Geothermal Sciences, Kyoto University, Annual Report FY 2002, 15-16, 2002.

Kagiyama, T., H. Utada, F. Masutani, T. Yamamoto, H. Murakami, Y. Tanaka, H. Masuda, T. Hashimoto, Y. Honkura, M. Mishina, H. Matsuwo, and H. Shimizu, MT observation and the estimated process of magma ascent, Report of Grant-in-Aid for Scientific Research (No. 03306009; Ohta, K.), 73-86, 1992 (in Japanese).

Kagiyama, T., T. Hashimoto, S. Wahyu, W. Kanda, Y. Tanaka, and M. Utsugi, Interaction of magma and water in Unzen volcano inferred from electromagnetic observation, 2002, Chikyu Monthly, 24(12), 858-865, 2002 (in Japanese)

Makino, M., T. Nakatsuka, R. Morijiri, Y. Okubo, S. Okuma, and
Y.Honkura, Derivation of three-dimensional distribution of geomagnetic anomalies from magnetic values at various elevations, Proc. 88th SEGJ Conf., Soc. Explor. Geophys. Japan, 502-507, 1993 (in Japanese). Mogi, T., Y. Tanaka, T. Morikawa, K. Kusakabe, M. Tanahashi, T. Nakatsuka, K. Tanaka, and H. Utada, Subsurface structure of UnzenFugen and Mayu-yama Volcano inferred from airborne electromagnetic method and magnetic survey, Bull. Volcanol. Soc. Japan, 40, 263-276, 1995 (in Japanese with English abstract).

Nakatsuka, T., Reduction of magnetic anomalies to and from an arbitrary surface, Butsuri-Tanko (Geophys. Explor.), 34, 332-339, 1981.

Nakatsuka, T., Aeromagnetic anomalies over the area of Unzendake volcano, J. Geomag. Geoelectr., 46, 529-540, 1994.

Nakatsuka, T., Minimum norm inversion of magnetic anomalies with application to aeromagnetic data in the Tanna area, Central Japan, J. Geomag. Geoelectr., 47, 295-311, 1995.

NEDO (New Energy Development Organization), Western district of Unzen, Rep. Promot. Dev. Geotherm., 15, 1060, 1988 (in Japanese).

Okubo, A., Y. Tanaka, M. Utsugi, N. Kitada, H. Shimizu, and T. Matsushima, Magnetization intensity mapping on Unzen Volcano, Japan, determined from high-resolution, low-altitude helicopter-borne aeromagnetic survey, Earth Planets Space, 57, 743-753, 2005.

Okuma, S., Magnetic constraints on the subsurface structure of AkitaYakeyama volcano, northeast Japan, Earth Planets Space, 50, 153-163, 1998.

Okuma, S., M. Makino, and T. Nakatsuka, Magnetization intensity mapping in and arround Izu-Oshima Volcano, Japan, J. Geomag. Geoelectr., 46, 541-556, 1994.

Tada, T., Spreading of the Okinawa trough and its relation to the crustal deformation in Kyushu, J. Seismol. Soc. Japan, 37, 407-415, 1984 (in Japanese with English abstract).

Tanaka, H., H. Hoshizumi, Y. Iwasaki, and H. Shibuya, Applications of paleomagnetism in the volcanic field: A case study of the Unzen Volcano, Japan, Earth Planets Space, 56, 635-647, 2004.

Utada, H., T. Kagiyama, T. Yamamoto, and Joint Research Group of Universities for Unzen Volcano, Deep resistivity structure in Unzen volcano by MT observation, Report of Grant-in-Aid for Scientific Research (No. 04302030; Ohta, K.), 64-71, 1994 (in Japanese).

Uto, K., N. Hoang, K. Oguri, H. Hoshizumi, and S. Uchiumi, History of volcano development and magma evolution in Shimabara peninsula, Chikyu Monthly, 24(12), 835-842, 2002. (in Japanese).

Webring, M. W., SAKI: A Fortran program for generalized linear inversion of gravity and magnetic profiles, U.S. Geol. Surv. Open File Rep., 85122, 104 pp., 1985.

A. Okubo (e-mail: ayako@svo.dpri.kyoto-u.ac.jp), T. Nakatsuka, Y. Tanaka, T. Kagiyama, and M. Utsugi 